\title{
DETERMINING THE PLASTIC STRAIN RESISTANCE OF METALLIC MATERIALS ON AN AUTOMATED PLASTOMETRIC COMPLEX
}

\author{
A. I. Potapov*, S. V. Gladkovsky, E. A. Kokovikhin, D. R. Salikhyanov, D. A. Dvoynikov \\ Institute of Engineering Science, Ural Branch of Russian Academy of Science, 34 Komsomolskaya st., Ekaterinburg, \\ Russian Federation \\ *Corresponding author. E-mail: potapov ai@list.ru; address for correspondence: ul. Komsomolskaya 34, 620049, \\ Ekaterinburg, Russian Federation. Tel.: +7 (343) 362-33-59; fax: +7 (343) 374-53-30
}

An overview of the main methods and equipment used to determine plastic strain resistance under compression tests is given. A testing technique for solid and build-up cylindrical specimens, as well as square cross-section ones, implemented on an automated plastometric complex is described in detail. The results of the evaluation of strain resistance obtained with the application of the developed methods for a large number of steels and alloys are presented.

Keywords: strain resistance, testing technique, tension, upset, plastometer, hardening curve for steels and alloys, carbjn and alloy steels, titanium alloy.

\section{References}

1. Gorelik S.S., Dobatkin S.V., Kaputkina L.M. Rekristallizatsiya metallov $i$ splavov [Recristallization of Metals and Alloys]. Moscow, MISIS Publ., 2005. 432 p. (In Russian).

2. $\quad$ Polukhin P.I., Gun G.Ya., Galkin A.M. Soprotivlenie plasticheskoy deformatsii metallov $i$ splavov. Spravochnik [Plastic strain resistance of Metals and Alloys. Reference book.]. Moscow, Metallurgiya Publ., 1983. 352 p. (In Russian).

3. Dao M., Chollacoop N., Van Vliet K.J., Venkatesh T.A., Suresh S. Computational modeling of the forward and reverse problems in instrumented sharp indentation. Acta materialia, 2001, vol. 49, pp. 3899-3918.

4. $\quad$ Bucaille J.L., Stauss S., Felder E., Michler J. Determination of plastic properties of metals by instrumented indentation using different sharp indenters. Acta materialia, 2003, vol. 51, pp. $1663-1678$.

5. Konovalov D.A., Smirnov S.V., Vichuzhanin D.I. Determination of strain resistance by results of indentation with conical indenters. Izvestiya vuzov. Chornaya Metallurgiya, 2007, no. 3, pp. 69-70. (In Russian).

6. Smirnov S.V., Smirnova E.O. A technique for determining the coefficients of the stressstrain diagram by nanoscratch test results. Journal of Materials Research, 2014, vol. 29, no. 16, pp. 1730-1736.

7. Potapov A.I., Mazunin V.P., Dvoynikov D.A., Kokovikhin E.A. A technique for studying strain resistance on a plastometric complex. Promyshlinnaya Laboratoriya, 2010, no. 6, pp. 59-63. (In Russian).

8. Honeycombe R.W.K. Plasticheskya deformatsiya metallov. [Plastic Deformation of Metals]. Moscow, Mir Publ., 1972. 406 p. (In Russian).

9. Mazunin V.P., Dvoynikov D.A. Increasing high-speed performance in the control of adjustable electric drives of mechanisms with elastic elements. Electrotekhnika, 2012, no. 10, pp. 36-42. (In Russian).

10. Zyuzev A.M., Dvoynikov D.A. Realization of the structure of high-speed electromechanical systems by means of the microcontroller of a Siemens Simoreg 6RA70 direct current thyristor converter. Elektrotekhnicheskie sistemy i kompleksy, 2014, no. 4 (25), pp. 17-20. (In Russian).

11. Unksov E.P. Inzhenernye metody rascheta usiliy pri obrabotke metallov davleniem [Engineering Methods for Calculating Forces in Metal Forming]. Moscow, Mashgiz Publ., 1955. 280 p. (In Russian). 
12. Migachev B.A. Soprotivlenie deformatsii $v$ mekhanike obrabotki davleniem [Strain Resistance in the Mechanics of Metal Forming]. Ekaterinburg, UrO RAN Publ., 1997. 176 p. (In Russian).

13. Konovalov A.V., Smirnov A.S. Identification of a strain resistance model by the results of compression tests. Promyshlennaya Laboratoriya, 2010, no. 1, pp. 53-56. (In Russian).

14. Konovalov A.V., Smirnov A.S. A visco-plastic model of strain resistance of steel $08 \mathrm{Kh} 18 \mathrm{~N} 10 \mathrm{~T}$ at a temperature of hot deformation. Metally, 2008, no. 2, pp. 55-59. (In Russian).

15. Sokolov L.D. On strain aging. Fizika Metallov i Metallovedenie, 1962, vol. 14, no. 6, pp. 904-909. (In Russian).

16. Krocha V.A. Uprochnenie metallov pri holodnoy plasticheskoy deformatsii. Spravochnik [Hardening of Metals by Cold Plastic Deformation. Reference book]. Moskow, Mashinostroenie Publ., 1980. 157 p. (In Russian).

17. Unksov E.P., Johnson W., Kolmogorov V.L. et al. Teoriya kovki i shtampovki. Uchebnoe posobie dlya studentov mashinostroitelnykh $i$ metIllurgicheskikh spetsialnostey vuzov [Theory of Forging and Stamping. Tutorial for students of machine-building and metallurgical specialties of higher education institutions], 2-e izd. pererab. i dop [2nd edition revised and expanded]. Moscow, Mashinostroenie Publ., 1992. 720 p. (In Russian).

18. Stolyarov V.V. Tensile testing of nanostructural materials. Promyshlennaya Laboratoriya, 2008, no. 1, pp. 54-57. (In Russian).

19. Potapov A.I., Gladkovsky S.V., Kokovikhin E.A., Mazunin V.P. Determination of strain resistance in sheet materials. Promyshlennaya Laboratoriya, 2011, no. 6, pp. 52-56. (In Russian).

20. Loginov Ju.N., Potapov A.I., Shalaev N.A. Effect of temperature and strain rate on the hardening of titanium sponge. Titan, 2012, no. 3 (37), pp. 36-42. (In Russian). 
УДК 620.162.2

\title{
ОПРЕДЕЛЕНИЕ СОПРОТИВЛЕНИЯ ПЛАСТИЧЕСКОЙ ДЕФОРМАЦИИ МЕТАЛЛИЧЕСКИХ МАТЕРИАЛОВ НА АВТОМАТИЗИРОВАННОМ ПЛАСТОМЕТРИЧЕСКОМ КОМПЛЕКСЕ
}

\author{
А. И. Потапов*, С. В. Гладковский, Е. А. Коковихин, Д. Р. Салихянов, Д. А. Двойников \\ Федеральное государственное бюджетное учреждение науки Институт машиноведения Уральского отделе- \\ ния Российской академии наук, ул. Комсомольская,34, Екатеринбург, Российская Федераџия \\ *Ответственный автор. Электронная почта: potapov_ai@list.ru; адрес для переписки: ул. Комсомольская, 34, \\ Екатеринбург, Российская федерация. Телефон: +7 (343) 362-33-59, факс: +7 (343) 374-53-30
}

Представлен краткий обзор методик и установок для определения сопротивления пластической деформации при испытаниях на сжатие. Подробно изложена методика испытаний на автоматизированном пластометрическом комплексе ИМАШ УрО РАН с использованием сплошных и составных цилиндрических образцов, а также образцов квадратного поперечного сечения. Представлены результаты определения сопротивления деформации ряда сталей и сплавов с использованием разработанных методик.

Ключевые слова: сопротивление деформащии, методика испытаний на сжатие, пластометр, кривые упрочнения сталей и сплавов, углеродистые и легированные стали, титановый сплав.

\section{1. Введение}

Сопротивление пластической деформации является важнейшей реологической характеристикой металлов и сплавов, определяющей энергосиловые параметры процессов обработки металлов давлением и характер течения металла, в частности распределение деформации по объему заготовки при её нагружении.

Информация о сопротивлении деформации в зависимости от степени, скорости и температуры деформирования необходима для практических расчетов конкретных технологических процессов ОМД и для компьютерного моделирования этих процессов, поэтому накопление базы данных по сопротивлению деформации различных металлов и сплавов в широком диапазоне изменения условий обработки актуально для исследователей.

В процессе холодной пластической деформации металлов и сплавов происходит их деформационное упрочнение или повышение сопротивления деформации $\sigma_{\mathrm{s}}$, в результате чего продолжение деформации возможно лишь при увеличении приложенного напряжения.

Состояние упрочненного (наклепанного) металла термодинамически неустойчиво, и при нагреве в металле происходят процессы разупрочнения, основными из них являются возврат и полигонизация, а при высоких температурах - рекристаллизация (первичная, собирательная и вторичная), при которых частично или полностью восстанавливаются структура и свойства деформированного металла [1]. Для некоторых металлов и сплавов при определенных температурно-скоростных условиях деформации может происходить разупрочнение уже в процессе деформирования (динамическое разупрочнение).

Характер кривых течения или зависимости сопротивления деформации $\sigma_{\mathrm{s}}$ от степени деформации $\varepsilon$ может различаться для разных по составу металлов и сплавов и в значительной мере зависит от температуры и скорости их нагружения [2]. Кривые течения можно разделить на четыре основных типа (рис.1). 


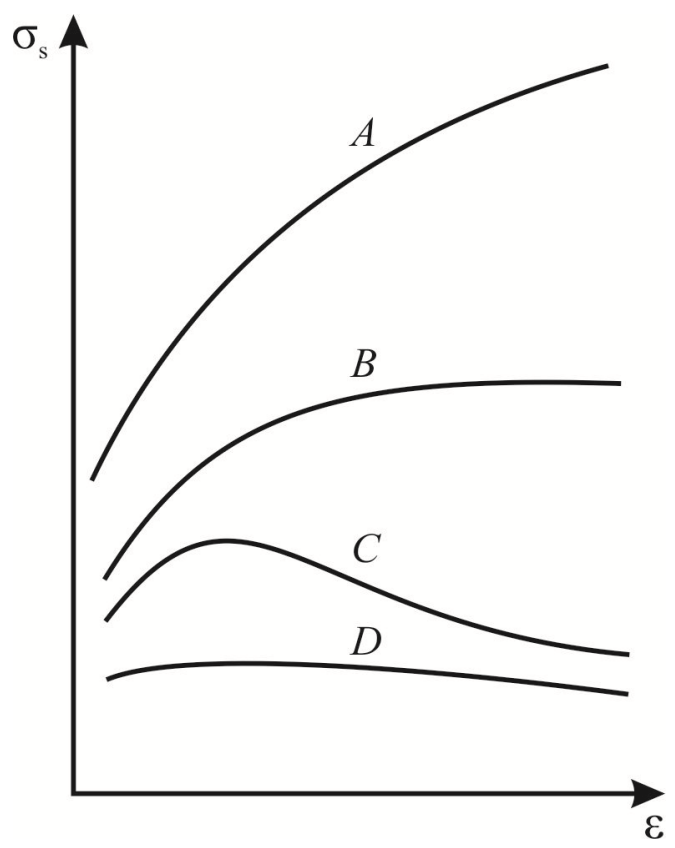

Рис. 1. Возможные варианты кривых течения металлов и сплавов при различных температурно-скоростных условиях деформации

На начальном этапе всех кривых имеет место более-менее интенсивное деформационное упрочнение. Для кривых типа $\boldsymbol{A}$ (см. рис.1) характерно наличие упрочнения на всем протяжении нагружения. При этом коэффициент упрочнения несколько снижается за счет процессов динамического возврата, полигонизации и теплового эффекта пластической деформации. Подобный вид кривых упрочнения характерен для динамического нагружения в условиях холодной, теплой, а иногда и горячей деформации, если металл разрушается раньше, чем на кривых $\sigma_{\mathrm{s}}-\varepsilon$, достигается область устойчивого течения.

Для кривых типа $\boldsymbol{B}$ сопротивление деформации по ходу нагружения постепенно стабилизируется (достигается установившаяся стадия течения), в металле более интенсивно проходят процессы динамического разупрочнения.

Наиболее характерным видом кривых течения металлов в условиях теплой и горячей деформации является кривая типа $\boldsymbol{C}$ с ярко выраженным максимумом значений $\sigma_{\mathrm{s}}$. У кривых типа $\boldsymbol{C}$ с ростом степени деформации в дополнение к динамическому возврату и полигонизации начинается и происходит динамическая рекристаллизация, что обусловливает снижение уровня $\sigma_{\mathrm{s}}$ В каждом конкретном случае ход кривой определяется также соотношением скоростей деформации и процессов полигонизации или (и) рекристаллизации.

При определенных условиях деформирования ряд сталей ведут себя как жесткопластические тела без заметного упрочнения (кривая типа D), например, среднеуглеродистые низколегированные стали при высоких температурах порядка $1200-1250{ }^{\circ} \mathrm{C}$ и низких скоростях деформации.

Сопротивление деформации принято определять при одноосном напряженном состоянии металла. Кроме того, в процессе испытания обеспечивают, как правило, постоянство температуры и скорости деформации образцов. Все это позволяет сравнивать результаты испытаний, полученные в разных работах на различном оборудовании, и согласно гипотезе единой кривой использовать эти результаты для расчетов более сложных по напряженнодеформированному состоянию процессов обработки давлением.

В практике исследований используются следующие методы определения сопротивления деформации: одноосное растяжение и сжатие (осадка), кручение и изгиб образцов [2].

Следует отметить также методы восстановления кривой сопротивления деформации по результатам индентирования. Так, в работе [3] описан алгоритм отыскания параметров 
кривой упрочнения методом одиночного внедрения острого индентора (пирамид Берковича, Виккерса или конического индентора). В работе [4] метод был развит для определения диаграммы деформационного упрочнения по результатам вдавливания нескольких инденторов с разными углами при вершине. В работе [5] для построения диаграмм деформационного упрочнения использовали различные типы инденторов - конусы с разными углами конусности, а в работе [6] предложен метод восстановления кривой деформирования по результатам вдавливания и царапания индентором Берковича.

Наиболее распространенным методом определения сопротивления деформации является метод сжатия (осадки) образцов. Достоинством этого метода является близость схемы деформации с основными процессами ОМД (ковкой, штамповкой, прокаткой, прессованием) как по напряженному, так и деформированному состоянию металла. Экспериментальное определение $\sigma_{\mathrm{s}}$ методом сжатия (осадки) осуществляется, как правило, на специальном оборудовании - пластометрах. Различные конструкции кулачковых и торсионных пластометров описаны в работе [2].

Большее распространение получили кулачковые пластометры, обеспечивающие заданное изменение (или постоянство) скорости деформирования образца в процессе испытания. Такого типа пластометры были установлены и работали в МИСИС (Москва), на Уралмашзаводе (Екатеринбург), в ЧПИ (Челябинск), в г. Добра (Чехия) и др. [2]. С использованием перечисленных пластометров получены данные по сопротивлению деформации большого числа сталей и сплавов при однократном и дробном нагружении.

В девяностые и более поздние годы в распоряжении отечественной науки появились универсальные испытательные машины типа «Инстрон» различных модификаций, работающие как на растяжение, так и на сжатие. Например, испытательные машины серии 5900 обеспечивают высокую точность и надежность при испытаниях на растяжение, сжатие и сдвиг с усилием до 50 кН (серия 5940) и до 600 кН (серия 5980) в диапазоне скоростей от $5^{-5}$ до 1016 мм/мин в зависимости от модели. Точность измерения нагрузки $\pm 0,5 \%$.

Следует также отметить зарубежные испытательные модули Pocket Jaw (усилие до 100 кН, скорость деформирующего инструмента до 2000 мм/с), Hydrawedge П (усилие сжатия до $200 \mathrm{\kappa H}$, скорость деформации при ударных испытаниях до $100 \mathrm{c}^{-1}$ ), универсальные испытательные машины фирмы Zwick/Roell (Германия), позволяющие проводить испытания на сжатие, растяжение и трехточечный изгиб в диапазоне нагрузок от 2 кг до 25 т при температурах $40-1200{ }^{\circ} \mathrm{C}$ и скоростях перемещения инструмента от 0,0005 до $600 \mathrm{Mm} / \mathrm{Mин}$.

В последние годы широкое распространение получают универсальные установки «Gleeble» фирмы «Dynamic System Inc» (США). Установки позволяют проводить горячие и теплые испытания как на растяжение (силой 100 кН), так и на сжатие (силой 200 кН) со скоростью деформации от $10^{-3}$ до $10^{3} \mathrm{c}^{-1}$. Нагрев до температуры испытания $\left(1750{ }^{\circ} \mathrm{C} \max \right)$ может осуществляться со скоростью до $10000^{\circ} \mathrm{C} / \mathrm{c}$ пропусканием тока через образец (контактным способом). Указанный способ нагрева обусловливает существенную неравно-мерность нагрева по длине испытуемых образцов и требует дополнительных приемов вы-равнивания температуры. Следует отметить также очень высокую стоимость установок типа «Gleeble» и энергоемкость проведения исследований на этих установках.

\section{2. Пластометрический комплекс ИМАШ УрО РАН}

В Центре коллективного пользования (ЦКП) «Пластометрия» Института машиноведения (ИМАШ) УрО РАН для определения сопротивления пластической деформации металлических материалов в течение ряда лет успешно используется пластометр кулачкового типа [7] с рабочей силой до $500 \mathrm{\kappa H}$, позволяющий с высокой степенью достоверности определять сопротивление деформации металлов и сплавов методом осадки в диапазоне степеней деформации $\varepsilon$ от 5 до $80 \%$ со скоростью $\xi$ деформации от $10^{-2}$ до $10^{2} \mathrm{c}^{-1}$ при температурах $T$ от 20 до $1400{ }^{\circ} \mathrm{C}$. Общий вид пластометра представлен на рис. 2. Пластометр имеет замкну- 
тую станину высокой жесткости, что обеспечивает высокую точность и надежность результатов испытаний [8].

С целью повышения точности воспроизведения заданных режимов экспериментов, расширения диапазона параметров испытаний и повышения достоверности результатов испытаний была проведена модернизация пластометра, в результате которой был создан автоматизированный пластометрический комплекс с новой тиристорной системой управления электроприводом Simoreg 6RA70 фирмы Сименс, включающей гибкую настройку параметров контуров управления по критериям быстродействия и демпфирования колебаний в механизме $[9,10]$, а также цифровой системой сбора и обработки данных, поступающих с датчиков усилий и перемещения, с использованием АЦП РCI-1713 фирмы Advantech и персонального компьютера.

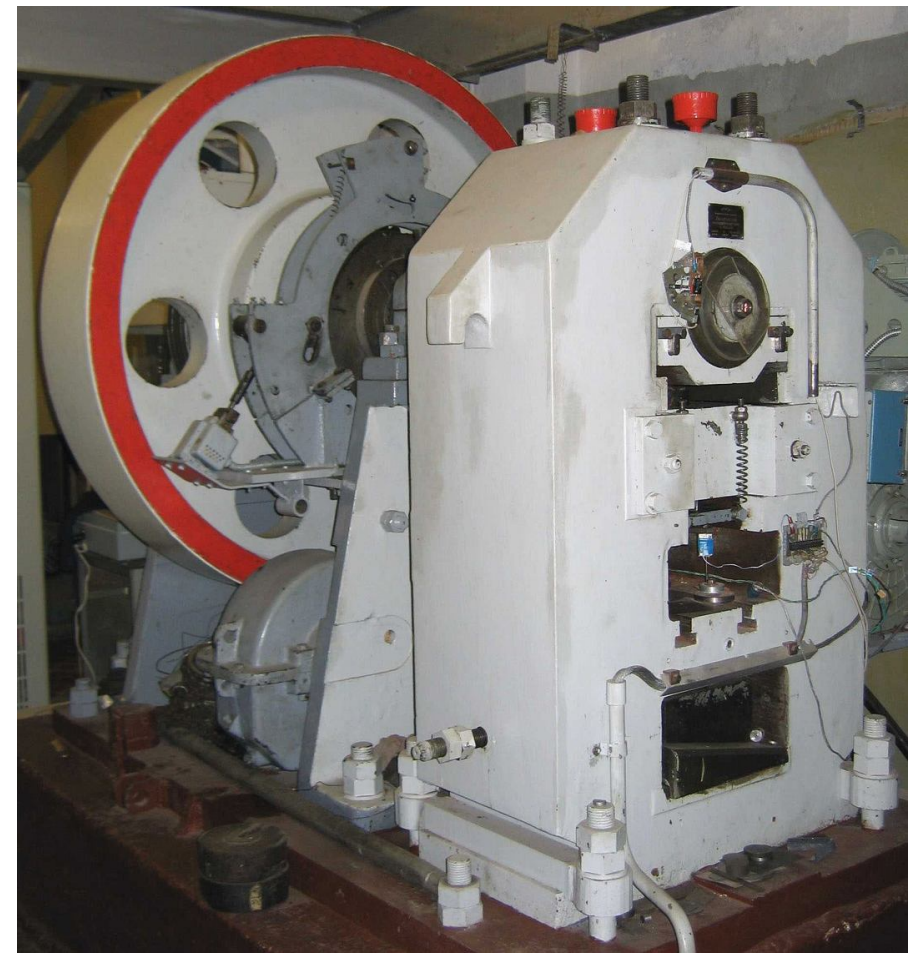

Рис. 2. Общий вид кулачкового пластометра ИМАШ УрО РАН

В состав комплекса входят:

a) пластометр Лысьвенского метзавода, модернизированный в части привода вращения кулачкового вала. Наряду с увеличением мощности двигателя привода в 4 раза (до 90 кВт) введён в работу широкодиапазонный реверсивный тиристорный преобразователь Simoreg 6RA70 (Siemens) с цифровыми программируемыми регуляторами, благодаря чему скорость вращения кулачкового вала поддерживается с отклонением не более $\pm 0,5 \%$ от заданной при любой нагрузке;

б) электропечь высокотемпературная камерная ПВК-1,4-25 с карбид-кремниевыми нагревателями КЭН-АПС и с термоконтроллером ТК10-1-2Р для нагрева образцов с погрешностью $\pm 0,5^{\circ} \mathrm{C}$ в диапазоне $400-1400{ }^{\circ} \mathrm{C}$;

в) система сбора и обработки информации на базе АЦП РСІ-1713 и персонального компьютера с программным обеспечением GeniDAQ. B GeniDAQ на базе стандартных функций реализуются циклы сбора информации 5 мс и более, что используется при малых скоростях испытаний, для циклов сбора информации до 0,01 мс в ИМАШ дополнительно разработан пакет WinDAQ;

г) быстродействующие датчики и измерительные устройства: тахометр привода ТМГ30П, мессдозы до 500 кН на основе тензометрического моста (погрешность до $250 \mathrm{H}$ при 
500 кН), резисторный измеритель перемещения ползуна - ходомер (ход до 15 мм) с погрешностью 16 мкм (ИМАШ).

Устройство рабочей (силовой) части пластометра представлено на рис. 3, где обозначены: 1 - станина, 2 - кулачковый вал, 3 - кулачковая обойма, в которой могут быть установлены четыре кулачка 4,5 - нажимной ролик, 6 - ползун, 7 - испытуемый образец в контейнере, 8 - ходомер, 9 - мессдоза, 10 - клиновой регулировочный механизм, 11 - профильный диск, 12 - датчик включения компьютерной записи процесса осадки, 13 - подушка подшипника скольжения кулачкового вала, 14 - возвратные пружины для ползуна.

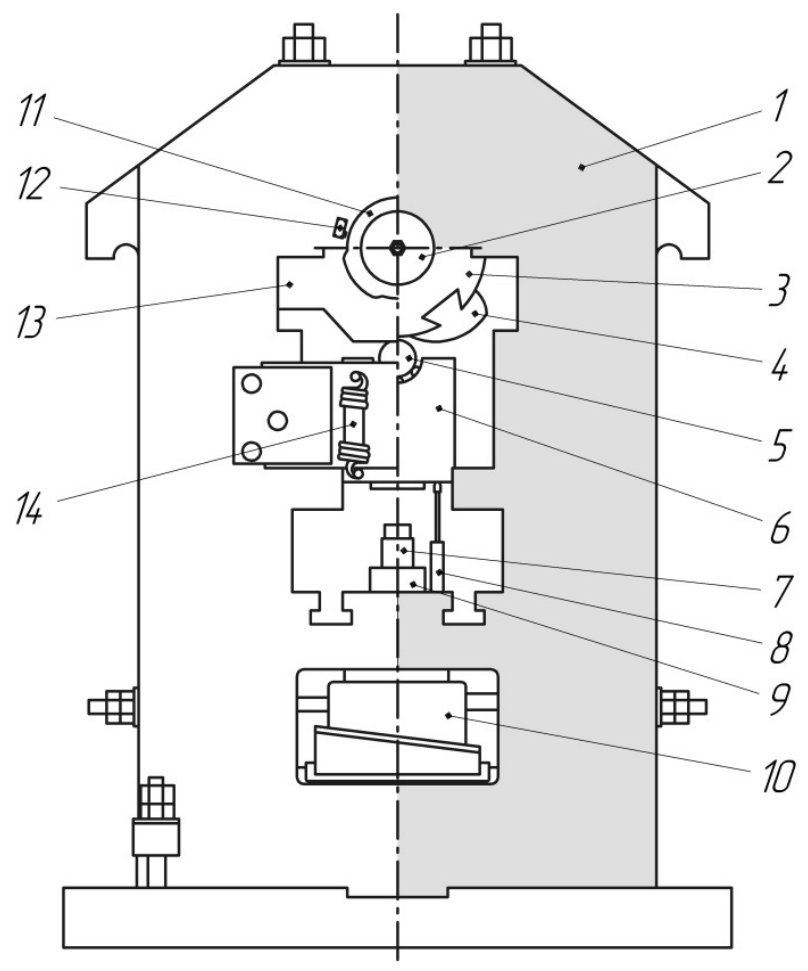

Рис. 3. Устройство силовой части пластометра ИМАШ УрО РАН (обозначения в тексте)

После включения муфты сцепления установленный на кулачковом вале 2 профильный кулачок 4 при вращении вала давит на ролик 5 и перемещает вниз ползун 6 , который бойками деформирует образец, находящийся в контейнере 7. Сила осадки измеряется мессдозой 9. По окончании осадки ползун возвращается в исходное положение пружинами 14. Bсе перечисленное монтируется в массивной станине 1 высокой жесткости. На случай заклинивания образца предусмотрен клиновой механизм 10.

\section{3. Методика и результаты испытаний на осадку объемных цилиндрических образцов}

Образцы испытываются при постоянной температуре и скорости деформации при осадке. С целью обеспечения постоянства температуры в процессе выдачи из печи и в процессе осадки образцы помещают в трубчатый контейнер между двумя деформирующими бойками, а пространство между образцом и стенкой контейнера заполняют каолиновой ватой (рис. 4).

Нагрев образцов в зависимости от температуры нагрева $\left(100-1250{ }^{\circ} \mathrm{C}\right)$ осуществляется в течение 58-15 минут (табл. 1) после посадки в электрическую печь, разогретую до заданной температуры. 
Таблица 1 - Время нагрева образца $\tau$ до заданной температуры испытания $T$

\begin{tabular}{|c|c|c|c|c|c|c|c|c|}
\hline$T,{ }^{\circ} \mathrm{C}$ & 200 & 400 & 600 & 800 & 900 & 1100 & 1200 & 1250 \\
\hline$\tau$, мин & 48 & 39 & 31 & 25 & 23 & 18 & 17 & 15 \\
\hline
\end{tabular}

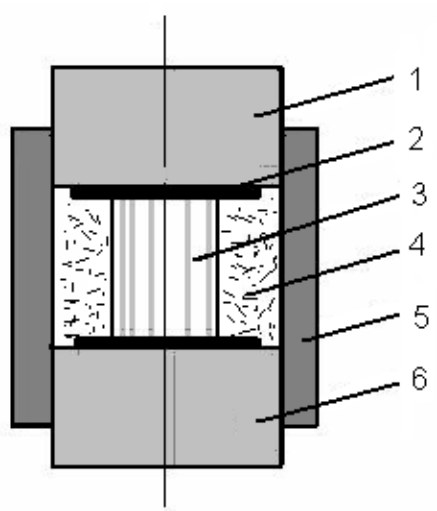

Рис. 4. Контейнер с образцом для нагрева и испытания: 1 - верхний боек; 2 - смазка; 3 - испытуемый образец; 4 - теплоизоляция (каолиновая вата); 5 - контейнер (труба); 6 - нижний боек

Постоянство заданной скорости деформации в процессе осадки, как отмечалось выше, обеспечивается приводом и профилем кулачка. Выбор настроек пластометра для выбранной скорости при проведении экспериментов осуществляется по табл. 2. Скорость деформации, как следует из табл. 2, определяется типом передачи (ременная или цепная) от двигателя к кулачковому валу, скоростью вращения двигателя $n_{\text {дв }}$ и профилем кулачка. В практике исследований используются два кулачка (см. табл. 2), которые позволяют осуществлять осадку образцов со скоростью деформации в пределах от 0,01 до $100 \mathrm{c}^{-1}$.

Таблица 2 - Настройка пластометра в зависимости от заданной скорости деформации

\begin{tabular}{|c|c|c|c|c|c|c|c|}
\hline \multicolumn{4}{|c|}{ Кулачок для малых скоростей деформации } \\
\multicolumn{3}{|c|}{ № 2} & \multicolumn{5}{|c|}{ Кулачок для больших скоростей деформации } \\
№ 1
\end{tabular}

Способ установки заданной скорости варьируется в зависимости от конкретной задачи. Так, например, осадка со скоростью деформации $1 \mathrm{c}^{-1}$ может быть осуществлена с использованием кулачка № 2 и цепной (при $n_{\text {дв }}=520$ об/мин) или ременной передачи $\left(n_{\text {дв }}=15,2\right.$ об/мин $)$.

Если же на пластометре установлен кулачок № 1, то та же скорость может быть получена с использованием цепной передачи при $n_{\text {дв }}=240$ об/мин или ременной передачи при $n_{\text {дв }}=7,1$ об/мин.

Поскольку скорость деформации при осадке определяется как $\xi=v / h$, где $v$ - скорость перемещения ползуна (мм/с) и $h$ - высота образца (мм) в текущий момент, постоянство скорости деформации будет зависеть как от профиля кулачка, так и от исходной высоты осаживаемого образца. В связи с этим каждый вновь изготовленный кулачок проходит проверку на зависимость фактического хода ползуна от угла поворота кулачкового вала, на основании 
которой строится график изменения скорости деформации $\xi$ по ходу осадки образцов различной исходной высоты.

В качестве примера на рис. 5 представлено изменение скорости деформации $\xi$ по ходу осадки образцов различной исходной высоты $h_{o}$ (цифры у кривых, мм) в зависимости от угла поворота кулачкового вала (кулачок № 1). Скорость деформации рассчитана для случая вращения вала со скоростью 1 град/с.

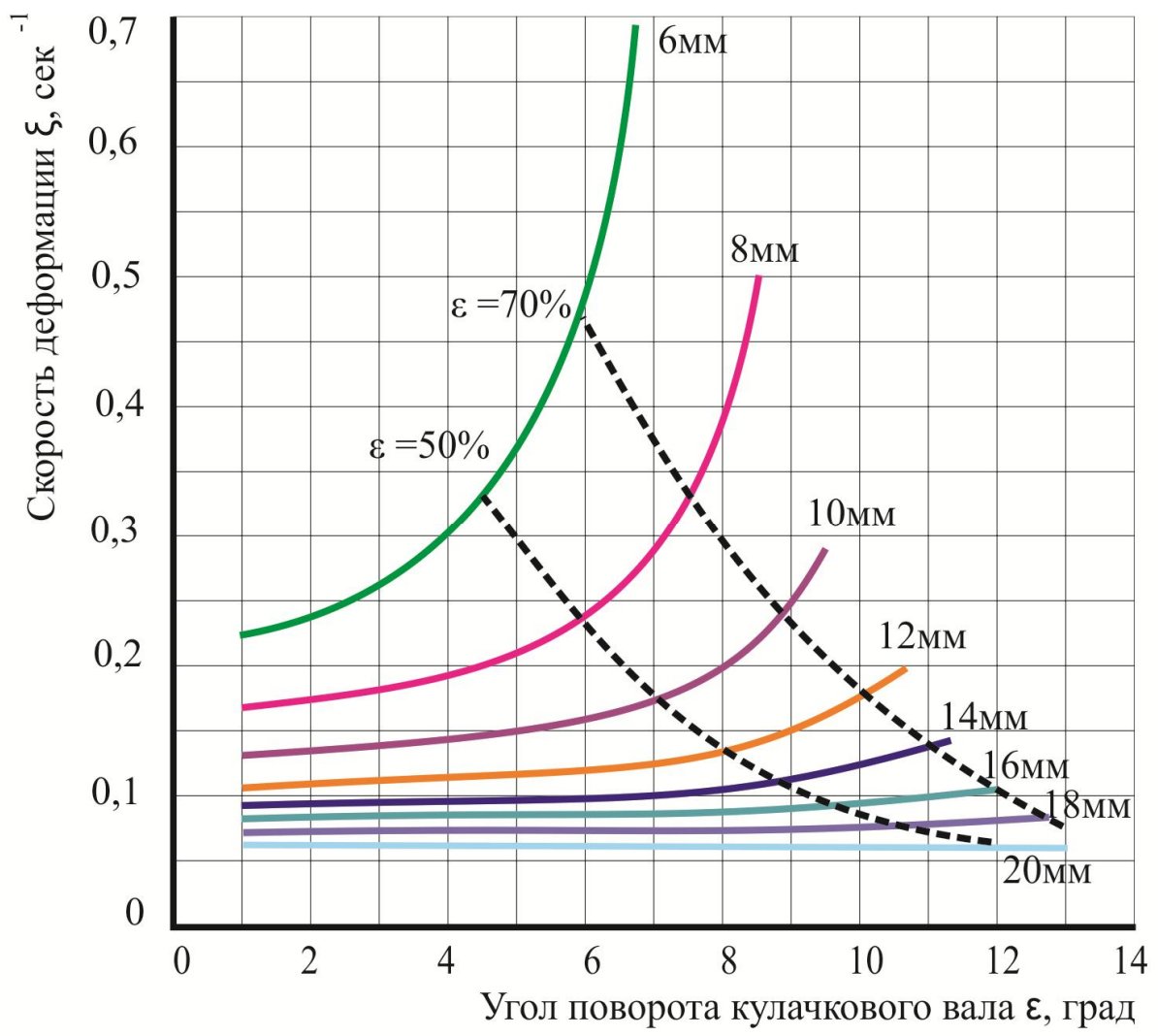

Рис. 5. Изменение скорости деформации $\xi$ по ходу осадки образцов различной исходной высоты $h_{o}$ в зависимости от угла поворота кулачкового вала (кулачок № 1)

Из анализа графика следует, что при использовании данного кулачка наилучшее постоянство скорости деформации обеспечивают образцы высотой 16-20 мм при степени осадки $\varepsilon$ до $70 \%$, и образцы высотой 14-20 мм при $\varepsilon$ до $50 \%$ от исходной высоты. Представленными данными руководствуются при выборе исходной высоты образцов для испытаний. Начальный диаметр образцов обычно выбирается из условия $d_{\mathrm{o}}=(1-0,7) h_{\mathrm{o}}$. Согласно [11] соотношение $h_{\mathrm{o}} / d_{\mathrm{o}}$ образца в пределах 1,0-1,5 обеспечивает минимальный коэффициент напряженного состояния $n_{\sigma}$, близкий к единице $\left(n_{\sigma}=1,0-1,02\right)$. В этом случае удельное давление при осадке примерно равно сопротивлению деформации материала образца ( $\left.p \approx \sigma_{\mathrm{s}}\right)$.

Для снижения трения на торцах и обеспечения напряженного состояния металла, близкого к одноосному сжатию, применяются смазки, состав которых подбирается в зависимости от температуры испытания [12]. Специальными опытами было установлено, что, например, при температурах $100-300{ }^{\circ} \mathrm{C}$ эффективно работает смесь барды сульфитного щелока с графитом, при $400-700{ }^{\circ} \mathrm{C}$ - поваренная соль, замешанная на жидком стекле, при температурах 800-900 ${ }^{\circ} \mathrm{C}$ - молотое оконное стекло, при более высоких температурах - стёкла более сложного состава.

В ряде случаев, несмотря на указанный выше выбор геометрии образцов, при применении неэффективной смазки имеет место бочкобразование на боковой поверхности осаженного образца, изменяющее напряженное состояние металла с одноосного на объемное. Это приводит к ошибке в определении сопротивления деформации (к некоторому завышению уровня $\sigma_{\mathrm{s}}$ ). 
В целях уменьшения этой ошибки в работах $[13,14]$ предложен метод идентификации кривых течения $\sigma_{\mathrm{s}}(\varepsilon)$, основанный на итерационном применении компьютерного моделирования процесса осадки образца и корректировки кривых упрочнения. Применение метода позволило уменьшить невязку расчетных и опытных значений силы деформирования. В этом методе при сжатии образцов коэффициент трения на контакте образца с деформирующим бойком определяется из условия наименьшего отклонения опытных и расчетных значений максимального и минимального диаметров боковой поверхности образца. Метод позволяет получать кривые течения в условиях, близких к одноосному сжатию (при минимальном трении на контакте образца и деформирующего бойка) независимо от фактических условий трения на контакте.

Сила осадки образца в экспериментах определяется мессдозой на основе тензометрического моста, которая перед каждой серией испытаний подвергается тарировке с использованием образцового манометра типа ДОСМ и компьютера. Пример компьютерной записи процесса осадки образца круглого сечения из стали $25 Г \mathrm{C}$ при температуре $800{ }^{\circ} \mathrm{C}$ приведен на рис. 6, где обозначены: 1 - график перемещения ползуна с бойком (шкала для ходомера справа); 2 - график изменения силы осадки (шкала для мессдозы слева); 3 - шкала временных точек отсчета.

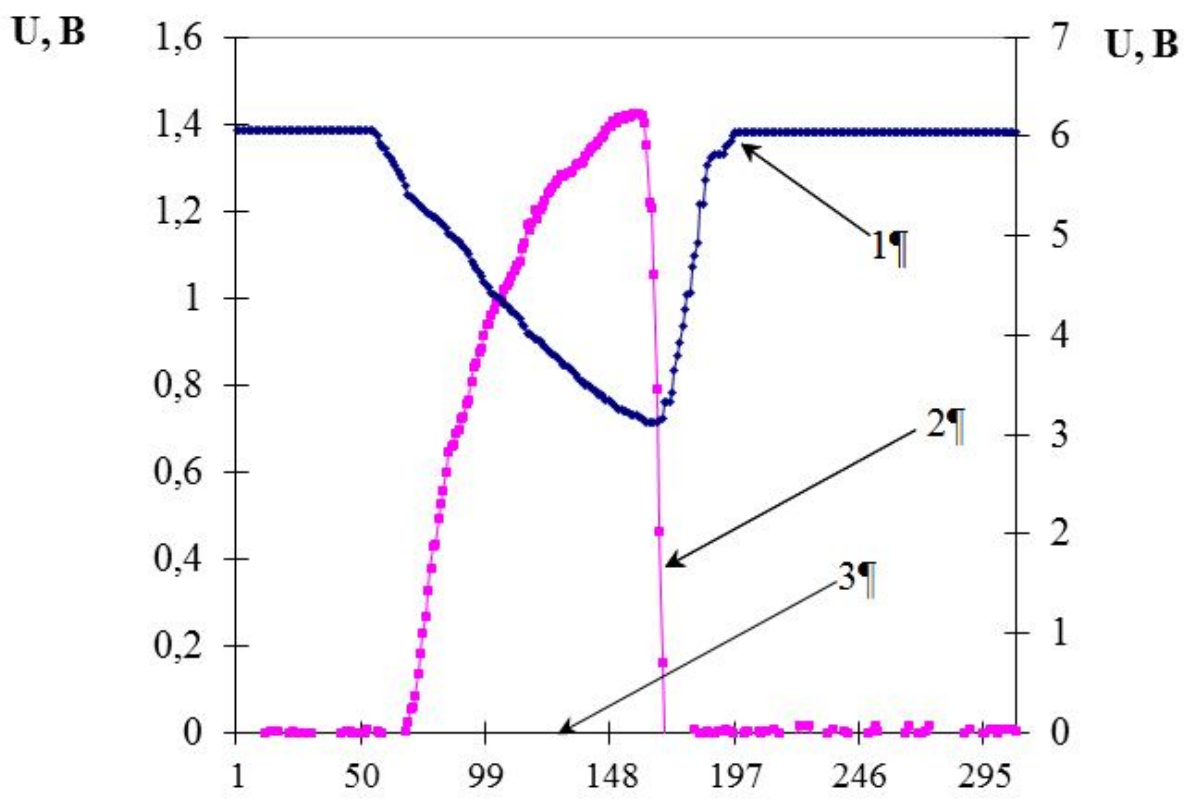

Рис. 6. Пример компьютерной записи процесса осадки образца (обозначения - в тексте)

Эти графики являются основой для построения кривых упрочнения исследуемых сталей и сплавов по специальной программе, разработанной в ИМАШ. Программа предусматривает получение зависимости $\sigma_{\mathrm{s}}=f(e)$, где $e$ - логарифмическая деформация, определяемая как е $=\ln h_{o} / h_{1}$, где $h_{1}-$ высота образца после осадки. Расчет сопротивления деформации в программе производится по формуле $\sigma_{\mathrm{s}}=P / F$, где $P$ - измеренная сила, $F$ - расчётная площадь поперечного сечения в данный момент времени. Вывод результатов (кривых течения) осуществляется в формате Microsoft Excel.

Для перевода показаний мессдозы и ходомера в вольтах $U$ в единицы силы (кН) или перемещения (мм) используются результаты их тарировки, по которой определяется, в частности, коэффициент $k$ в формуле $P=k U$.

С использованием представленной выше методики проведено исследование сопротивления деформации ряда сталей и сплавов в широком диапазоне скоростей деформирования $\xi$ (от 0,1 до $\left.70 \mathrm{c}^{-1}\right)$ при температурах холодной $\left(20-400{ }^{\circ} \mathrm{C}\right)$, теплой $\left(500-700{ }^{\circ} \mathrm{C}\right)$ и горячей $\left(800-1250{ }^{\circ} \mathrm{C}\right)$ деформации. В частности, проведено испытание армко-железа, углеро- 
дистых сталей марок 10, 20 и 50, сталей для арматуры 08Г2С, 25ГС, 35Г2, мартенситностареющих сталей 03Х11Н10М2Т1 (ЭП679) и типа 03Х14Н10К5М2ЮТ с варьированием химического состава, титановых сплавов ВТ6, ВТ8, ВТ3-1, ВТ20, ВТ22 и др.

Сталь 20 (0,24\% C, 0,18\% Si, 0,57\% Mn, 0,11\% Ni, 0,12\% Cr) подвергалась испытанию при температурах холодной и теплой деформации $\left(20,100,200,300,400,500\right.$ и $\left.600{ }^{\circ} \mathrm{C}\right)$ и скоростях деформации $\xi=0,5 ; 1,0 ; 10,0$ и $70 \mathrm{c}^{-1}$. В качестве примера на рис. 7 представлены кривые течения стали 20 при температурах 20, 200, 400 и $600{ }^{\circ} \mathrm{C}$.

Общей закономерностью кривых течения стали 20 является уменьшение интенсивности упрочнения с ростом степени деформации и с повышением температуры. При комнатной температуре (см. рис. 7 a) характер кривых течения меняется с увеличением скорости деформации. При малых скоростях идет монотонное упрочнение металла с увеличением сопротивления деформации в процессе всего обжатия образца, а максимальное значение $\sigma_{\mathrm{s}}$ достигается лишь в конце процесса. С увеличением скорости упрочнение на начальном этапе осадки идет все более интенсивно, а к концу процесса осадки возможно динамическое разупрочнение металла со снижением величины $\sigma_{\mathrm{s}}$. При степени деформации $e=0,7$ величина $\sigma_{\mathrm{s}}$ практически одинакова для всех скоростей. Аналогичный ход кривых упрочнения был установлен нами ранее [7] для армко-железа и углеродистых сталей марок Ст3 и 50.

При низких температурах 20, 100 и $200{ }^{\circ} \mathrm{C}$ на кривых течения наблюдается зуб текучести, который отсутствует при более высоких температурах. Зуб текучести - по сути, резкое снижение напряжения перед появлением пластической деформации. Он имеет дислокационное происхождение. Отметим, что фиксирование зуба текучести на кривых течения согласно [8] свидетельствует о высокой надежности методики и достоверности результатов испытаний, в том числе получаемых на пластометрическом комплексе ИМАШ УрО РАН.

При температурах $400-600{ }^{\circ} \mathrm{C}$ с повышением скорости деформации величина $\sigma_{\mathrm{s}}$ возрастает. На кривых течения при температуре $200{ }^{\circ} \mathrm{C}$, при которой начинаются процессы деформационного старения металла [15] возможна обратная зависимость сопротивления деформации от скорости деформации.

Полученные нами результаты исследования (кривые течения) стали 20 хорошо согласуются с данными Бюхлера, приведенными в работе [16], для углеродистой стали С15 $(0,15 \%$ C, 0,47 \% Mn, 0,30 \% Si), которая была испытана при температурах 20, 200, 300 и $500{ }^{\circ} \mathrm{C}$ со скоростями деформации 0,$25 ; 1,6 ; 8,0$ и 40,0 $\mathrm{c}^{-1}$.

Зависимость сопротивления деформации стали 20 от температуры при разных скоростях деформации, представленная на рис. 8, свидетельствует о том, что увеличение скорости деформации сдвигает максимум величины $\sigma_{\mathrm{s}}$ в сторону более высоких температур. По этой причине для температур теплой деформации в интервале $200-300{ }^{\circ} \mathrm{C}$ может нарушаться классическое (обычное) снижение сопротивления деформации с повышением скорости. Отметим, что аналогичный результат был получен Л. Д. Соколовым [15], который объясняет этот факт деформационныл старением сталей при температурах около $200-400{ }^{\circ} \mathrm{C}$. В этом интервале температур металл имеет также провал пластичности. Это явление известно в литературе как синеломкость [17]. Оно характерно, в частности, для перлитных сталей, к которым относится сталь 20. 


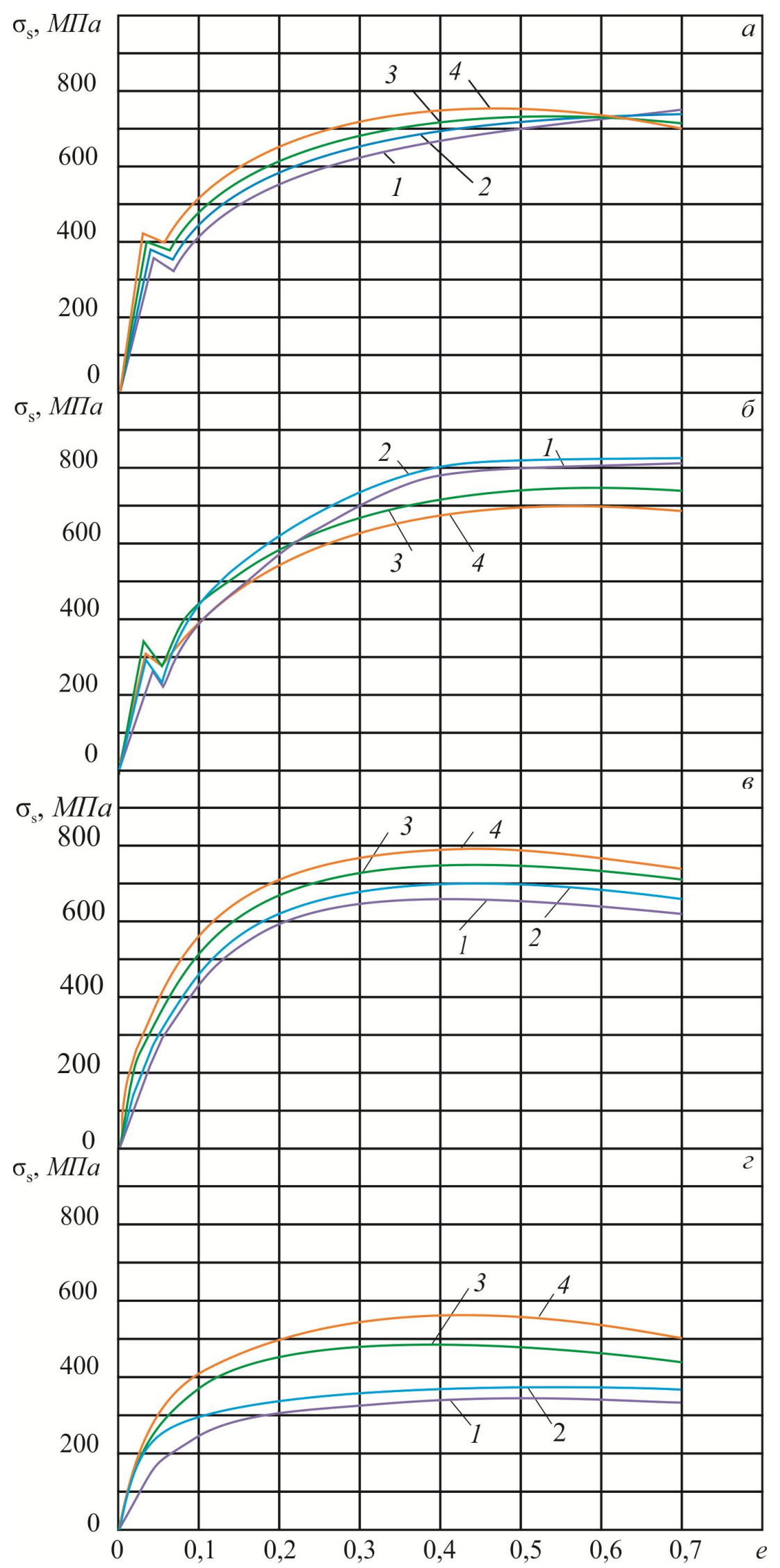

Рис. 7. Кривые течения стали 20 в зависимости от степени $e$ и скорости деформации $\left(1-0,5 \mathrm{c}^{-1}, 2-1 \mathrm{c}^{-1}, 3-10 \mathrm{c}^{-1}, 4-70 \mathrm{c}^{-1}\right)$ при температурах $20(a), 200\left(\right.$ б), $400\left(\right.$ (в) и $600{ }^{\circ} \mathrm{C}($ (c) 


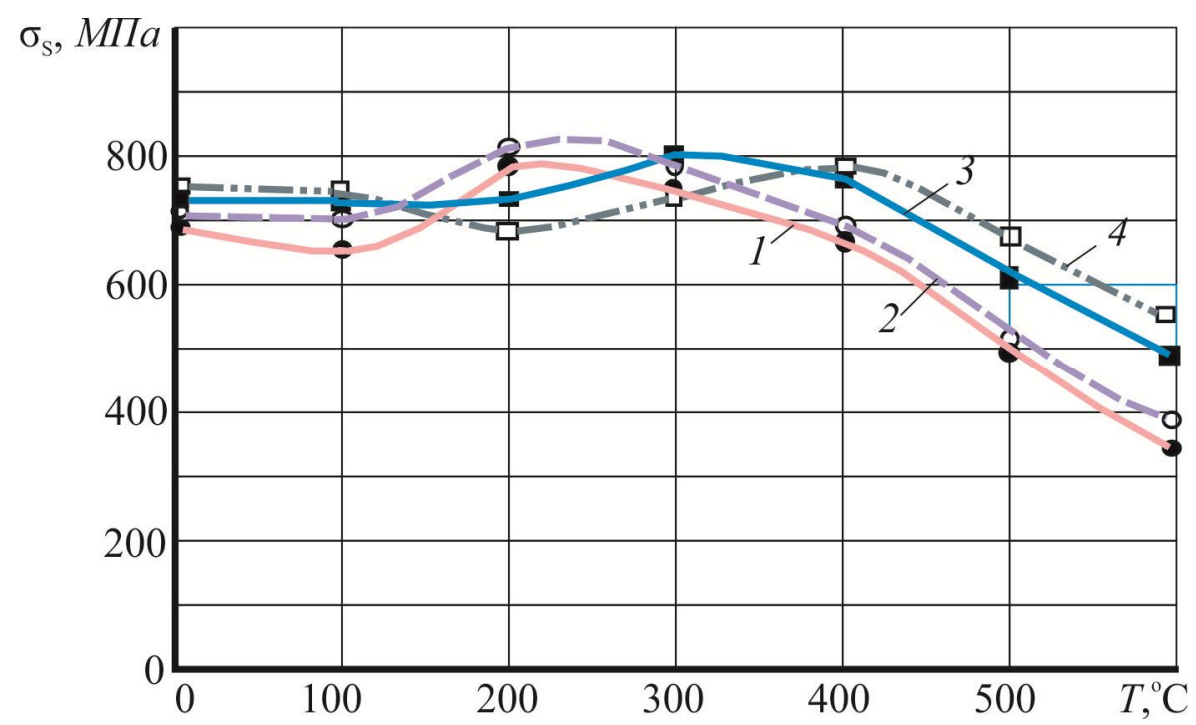

Рис. 8. Зависимость сопротивления деформации стали 20 от температуры испытания и скорости деформации $\xi\left(1-0,5 \mathrm{c}^{-1}, 2-1 \mathrm{c}^{-1}, 3-10 \mathrm{c}^{-1}, 4-70 \mathrm{c}^{-1}\right)$ при степени деформации $e=0,45 \pm 0,05$

На рис. 9 и 10 приведены результаты исследования* сопротивления деформации мартенситно-стареющих сталей типа Х15Н10К6М3ТЮ при температурах холодной, теплой и горячей деформации и скорости деформации $\xi=1 \mathrm{c}^{-1}$. Химический состав сталей представлен в табл. 3.

Таблица 3 - Химический состав исследованных мартенситно-стареющих сталей

\begin{tabular}{|c|c|c|c|c|c|c|c|c|c|}
\hline \multirow{2}{*}{ № плавки } & \multicolumn{7}{|c|}{ Содержание элементов, масс. \% } \\
\cline { 2 - 11 } & $\mathrm{C}$ & $\mathrm{Si}$ & $\mathrm{Mn}$ & $\mathrm{Cr}$ & $\mathrm{Ni}$ & $\mathrm{Mo}$ & $\mathrm{Co}$ & $\mathrm{Ti}$ & $\mathrm{Al}$ \\
\hline 1 & 0,08 & 0,29 & 0,18 & 14,56 & 9,8 & 2,75 & 5,64 & 0,47 & 0,72 \\
\hline 2 & 0,05 & 0,23 & 0,21 & 14,8 & 9,55 & 2,81 & 5,46 & 0,53 & 0,85 \\
\hline
\end{tabular}

* Результаты получены в рамках совместной работы с д.т.н., проф. Л.А.Мальцевой (УрФУ им. первого Президента России Б.Н.Ельцина)

Potapov A. I. et al. / Determining the plastic strain resistance of metallic materials on an automated plastometric complex 


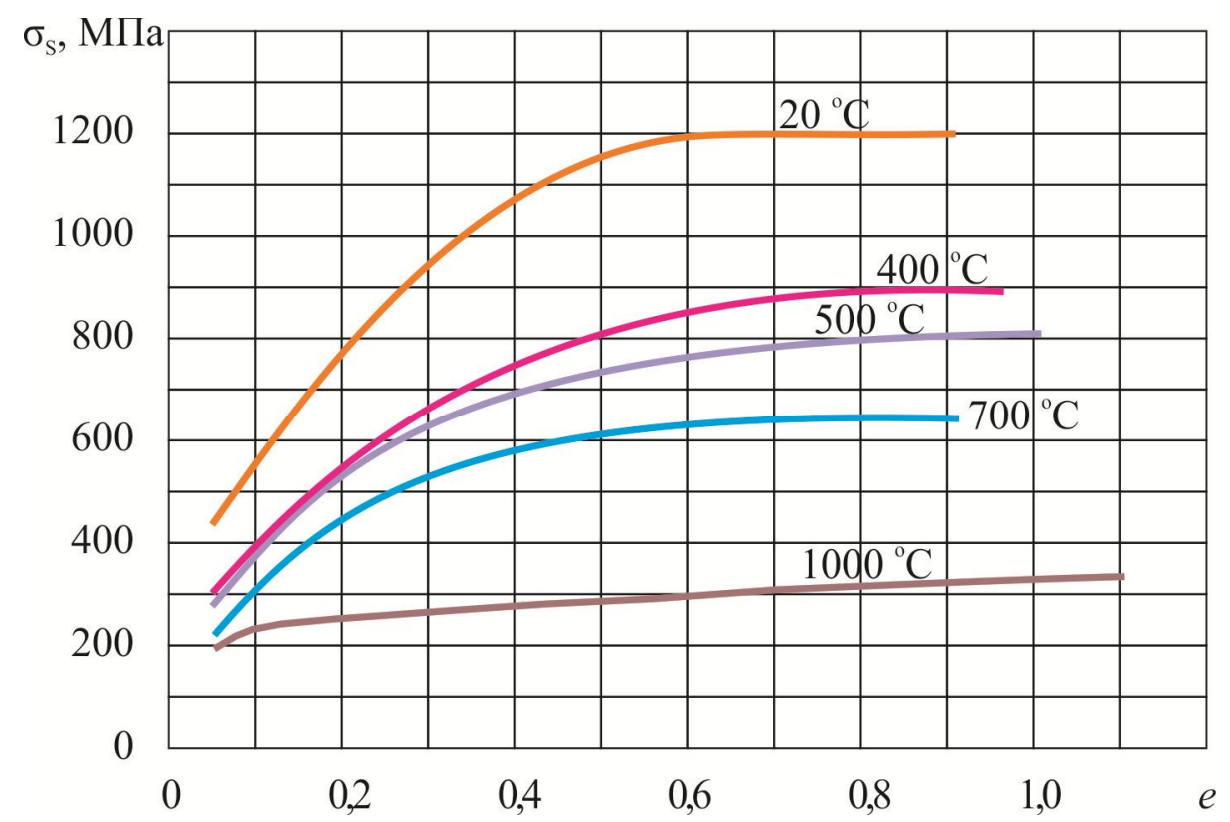

Рис. 9. Кривые течения мартенситно-стареющей стали плавки 1 (табл. 2) при различных температурах

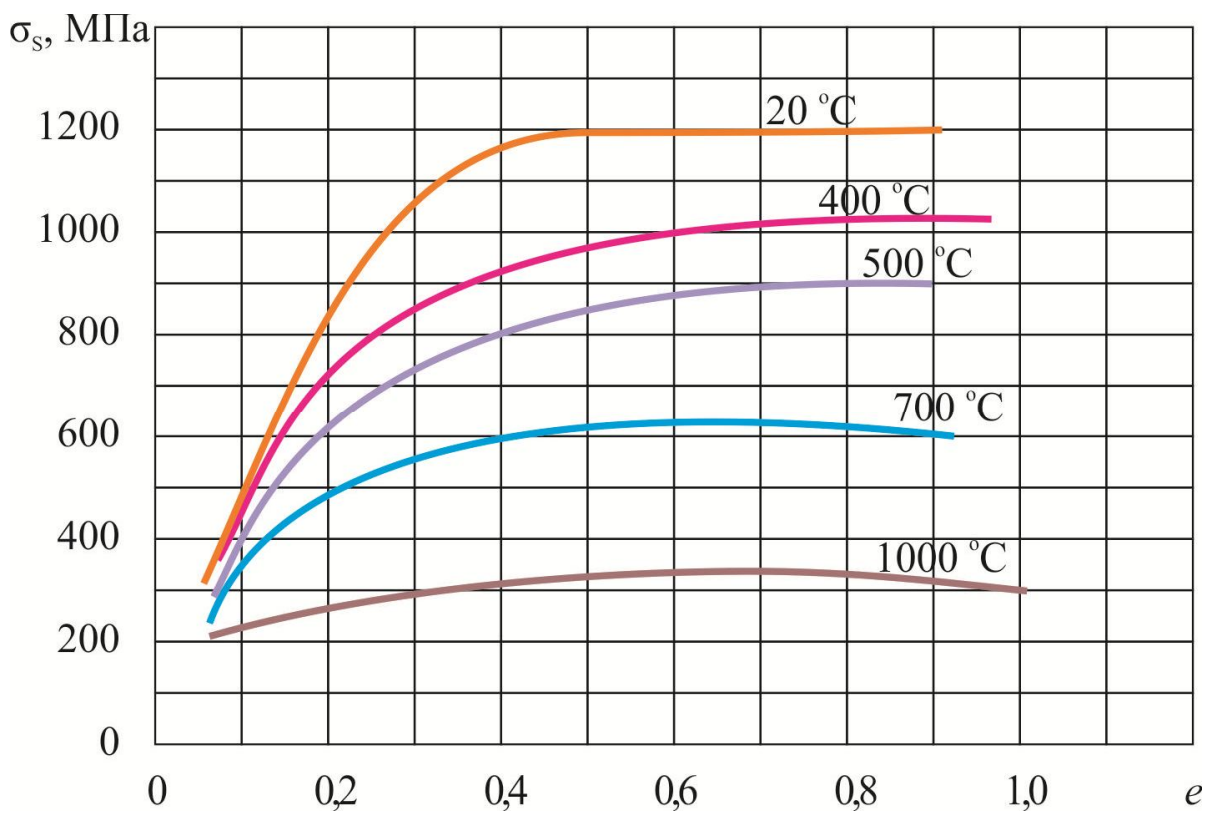

Рис. 10. Кривые течения мартенситно-стареющей стали плавки 2 (табл. 2) при различных температурах

Анализ и сопоставление кривых течения свидетельствуют о том, что они являются типичными для сталей такого класса. Исследуемые мартенситно-стареющие стали отличаются относительно высоким уровнем сопротивления деформации при всех температурах испытания (при холодной, теплой и горячей деформации). Наибольшее упрочнение металла всех плавок, естественно, имеет место при холодной деформации $\left(20^{\circ} \mathrm{C}\right)$. После достижения некоторого максимума возможно снижение $\sigma_{\mathrm{s}}$ за счет процессов динамического разупрочнения. При теплой деформации $\left(400-700{ }^{\circ} \mathrm{C}\right)$ упрочнение металла плавки 2 идет также достаточно интенсивно. И только при горячей деформации $\left(1000^{\circ} \mathrm{C}\right)$ уровень $\sigma_{\mathrm{s}}$ остается низким и | практически неизменным при увеличении степени деформации до $e=\_1$. Для обоих составов 
существенное снижение уровня $\sigma_{\mathrm{s}}$ имеет место при температуре $700{ }^{\circ} \mathrm{C}$. При этой температуре уже возможна практическая реализация теплой деформации сталей.

\section{4. Методика и результаты испытаний на осадку составных цилиндрических образцов}

Для расчета усилий и других энергосиловых параметров таких процессов, как накопительная пакетная прокатка, прокатка слоистых металлических материалов, необходима информация о сопротивлении деформации материала отдельных слоев или пакета в целом. С учетом гипотезы единой кривой данные о сопротивлении деформации могут быть взяты из результатов испытания на растяжение листовых образцов. Однако имеются экспериментальные данные [18], показывающие, что при переходе от массивных к тонким листовым образцам механические свойства металлов и сплавов существенно меняются. Поэтому в ряде случае целесообразно определение сопротивления деформации путем осадки объемных составных образцов, сформированных из листовых заготовок.

С этой целью в качестве метода определения сопротивления деформации листовых материалов разработана и предложена осадка объемных цилиндрических образцов [19], составленных из листовых шайб (рис. 11), которые могут быть изготовлены вырубкой из листового материала в специальном устройстве (вырубном штампе).

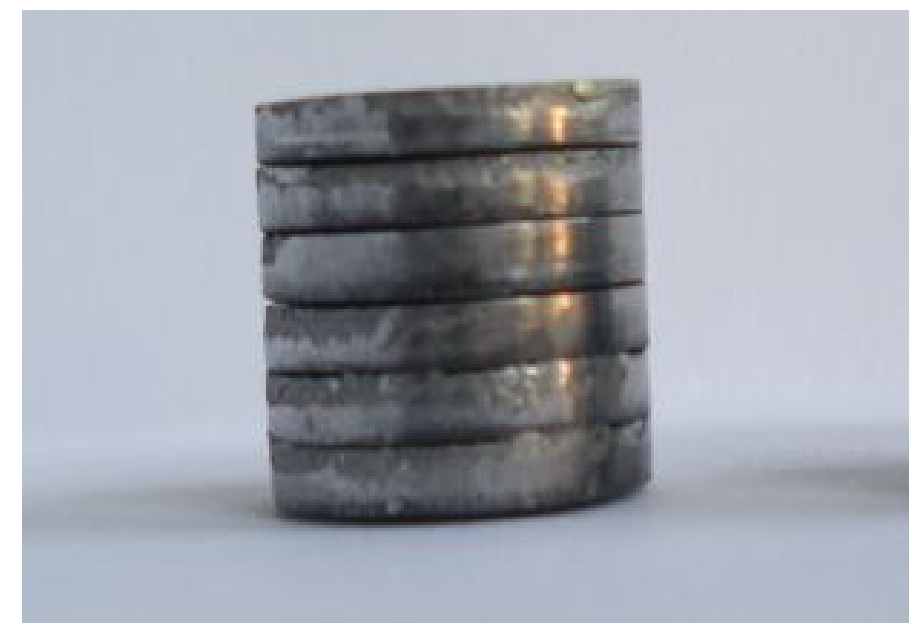

Рис. 11. Общий вид составного цилиндрического образца перед испытанием

В работе [19] на основе сравнения результатов испытаний сплошных и составных образцов из материала одного химического состава установлена правомерность использования предложенного нами метода осадки составных образцов для определения величины $\sigma_{\mathrm{s}}$ листового материала.

В качестве примера на рис. 12 представлены кривые упрочнения стали Ст3, а на рис. 13 - титанового сплава ВТ3-1, полученные по результатам испытаний сплошных и составных образцов, изготовленных для чистоты эксперимента из одних и тех же заготовок (шайбы для составных образцов были выточены на токарном станке). Из анализа графиков видно хорошее совпадение кривых упрочнения и значений $\sigma_{\mathrm{s}}$, полученных при испытаниях сплошных и составных образцов. Данные получены при скорости деформации $\xi=1,0 \mathrm{c}^{-1}$. 


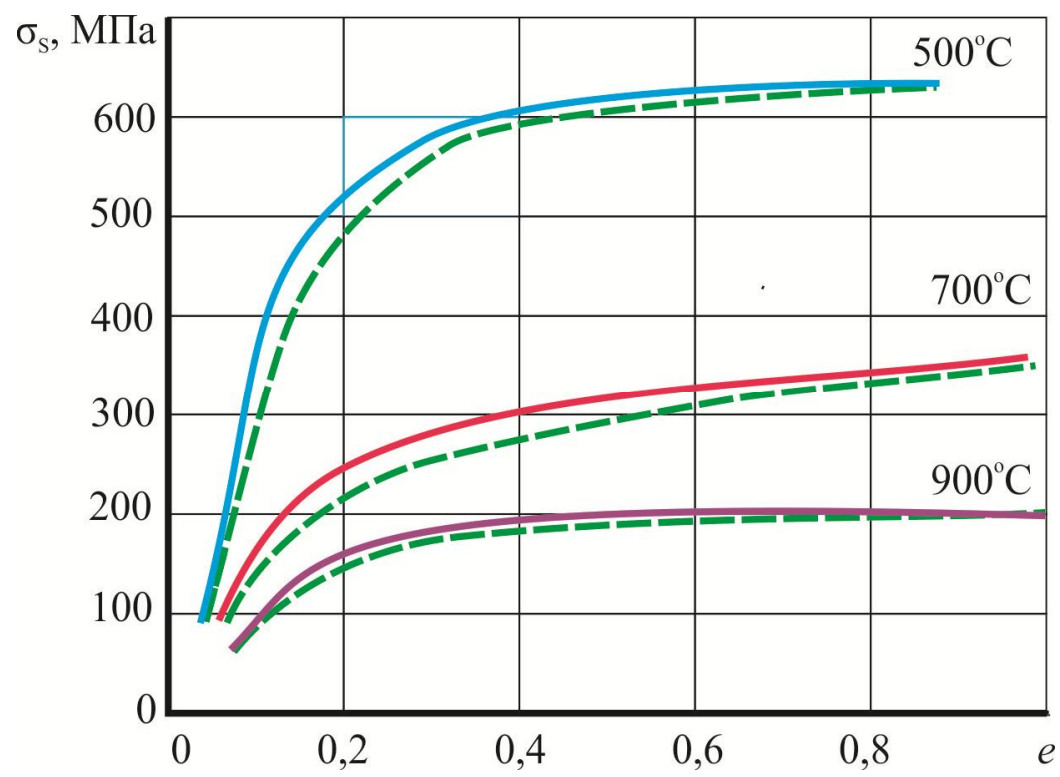

Рис. 12. Кривые течения стали Ст3 по результатам экспериментов по осадке сплошных сплошные кривые и составных пунктирные кривые образцов при различных температурах

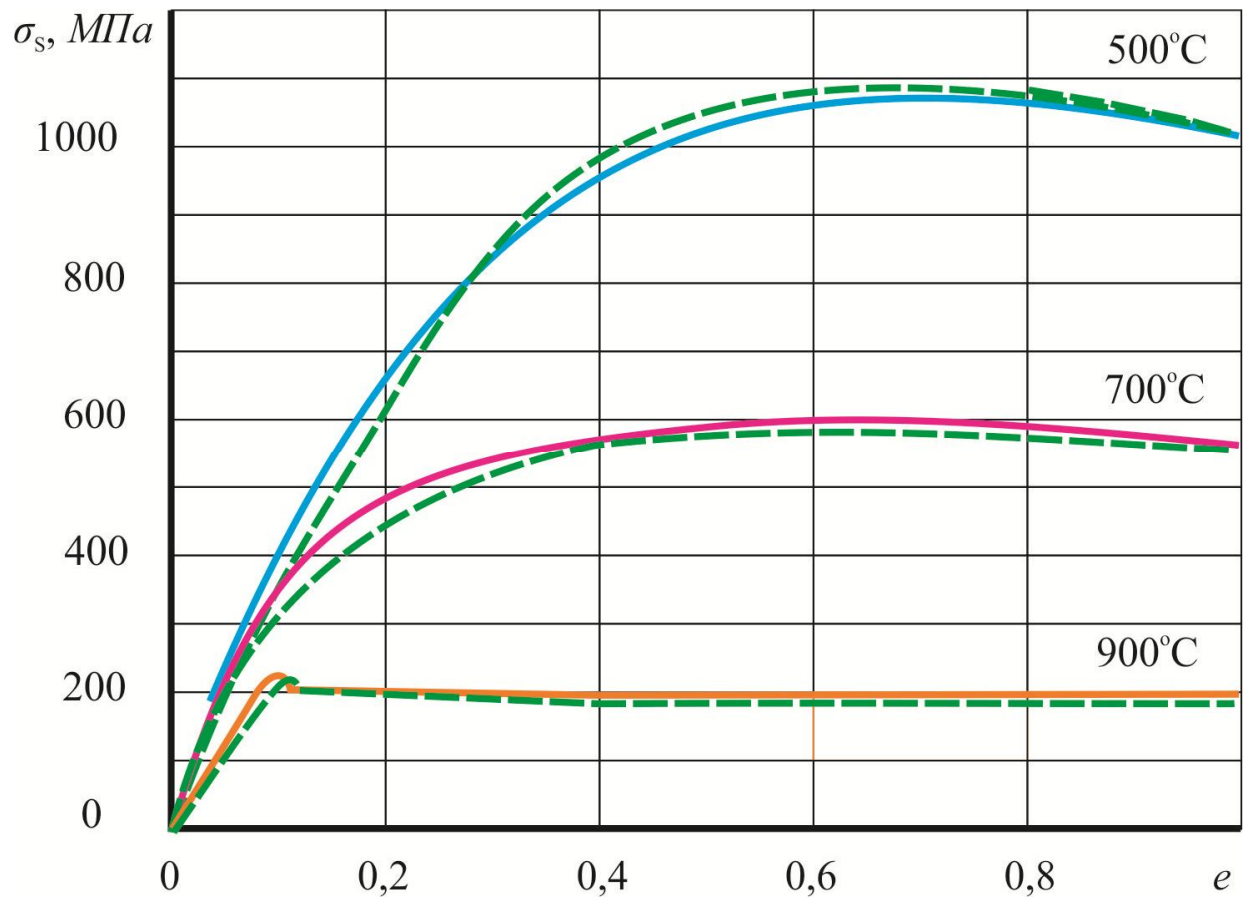

Рис. 13. Кривые течения титанового сплава ВТ3-1 по результатам экспериментов по осадке сплошных сплошные кривые и составных пунктирные кривые образцов при различных температурах

Приведенные данные свидетельствуют о правомерности использования данного метода для оценки сопротивления деформации как листовых, так и объемных заготовок исследуемого материала.

Предложенный метод был использован также для определения сопротивления деформации листовой стали 006/IF. На рис. 14 представлены кривые течения стали 006/IF, полученные осадкой образцов, составленных из шайб, вырубленных из листового проката этой стали. 
Сталь имела следующий химический состав (масс. \%): 0,056 C; 0,123 Mn; 0,002 Si; 0,0059 P; 0,0040 S; 0,024 Cr; 0,0020 Ni; 0,006 N.

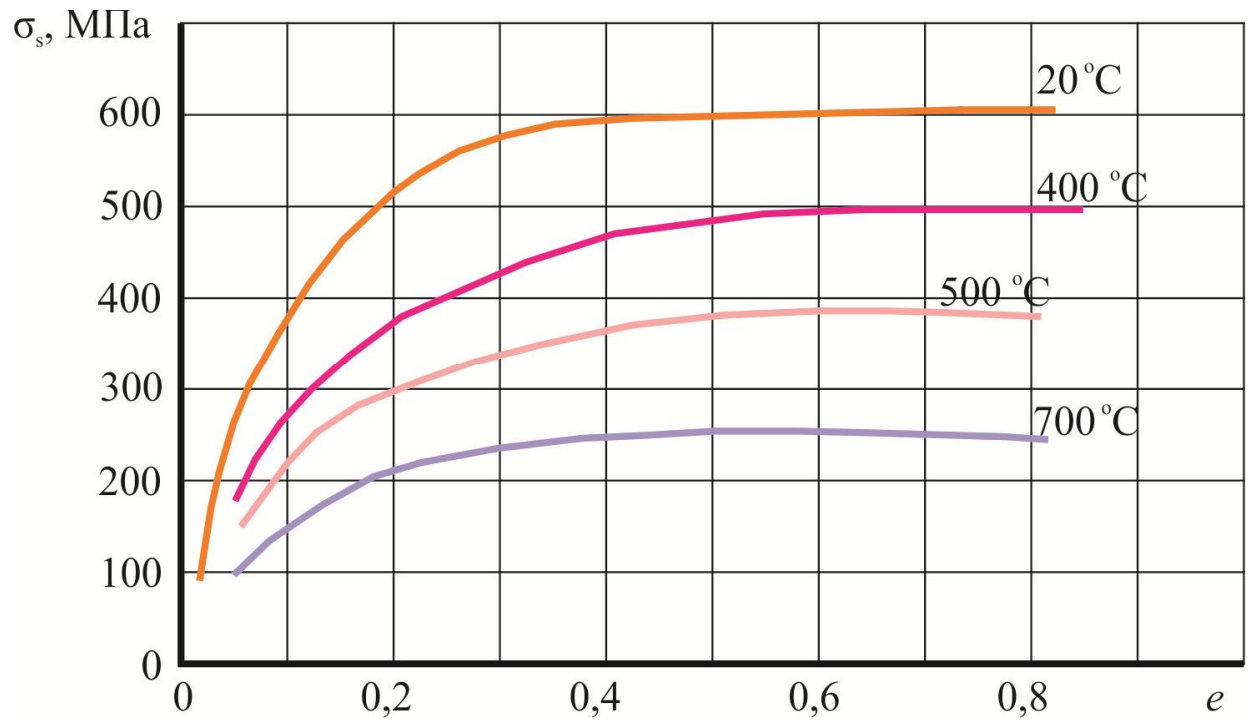

Рис. 14. Кривые течения стали 006/IF при холодной, теплой и горячей деформации. Скорость деформации $1,0 \mathrm{c}^{-1}$

Результаты испытаний свидетельствуют о том, что сталь 006/IF имеет низкий уровень сопротивления деформации при всех исследованных температурах, в том числе и в холодном состоянии. Для неё характерно также относительно слабое упрочнение с ростом степени деформации.

\section{5. Методика и результаты испытаний на осадку образцов квадратного (прямоугольного) поперечного сечения}

Ниже рассмотрена методика определения сопротивления деформации на пластометрическом комплексе с применением образцов квадратного (прямоугольного) поперечного сечения. Необходимость использования таких образцов может возникнуть в исследовательской практике при наличии проката или кованых прутков квадратного (прямоугольного) поперечного сечения из исследуемой стали. При этом отпадает необходимость изготовления из них цилиндрических образцов на токарных станках. Образцы изготавливаются лишь разрезкой прутков на соответствующие длины.

Впервые методика была опробована при исследовании сопротивления деформации титановой губки [20] после разделки ее на отдельные куски.

Для подтверждения правомерности использования предлагаемой методики проведен следующий эксперимент: из проката углеродистых стали (сталь 10) сечением 9,8 × 9,8 мм были изготовлены образцы указанных квадратных сечений высотой $15+0,2$ мм. Другая часть того же катаного прутка была переточена на токарном станке на образцы диаметром 9,3 мм. Те и другие образцы были испытаны на пластометрическом комплексе в одинаковых условиях. В частности нагрев их в печи осуществлялся в одной садке.

Кривые течения стали 10, полученные осадкой образцов круглого и квадратного сечения, представлены на рис. 16. 


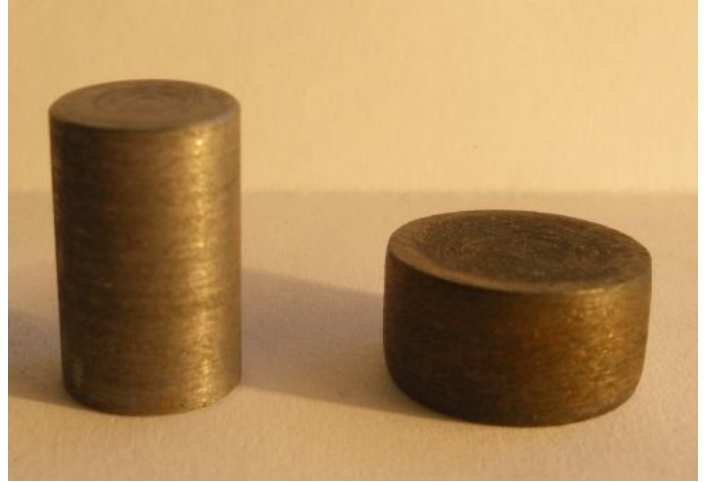

$a$

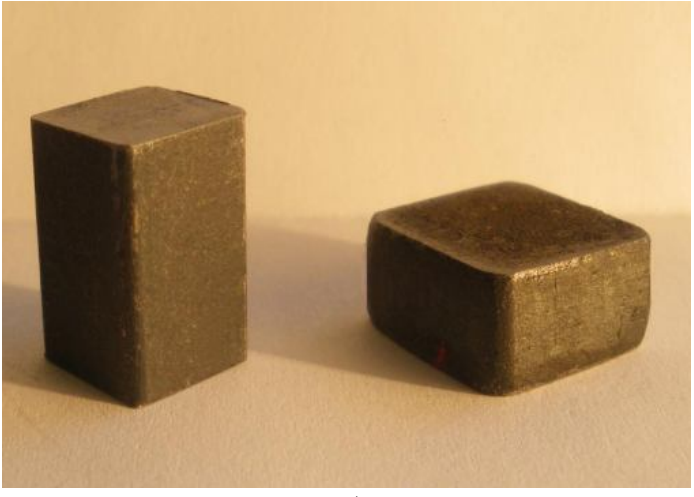

6

Рис. 15. Внешний вид цилиндрических образцов (a) и образцов квадратного сечения (б) до и после осадки на пластометре

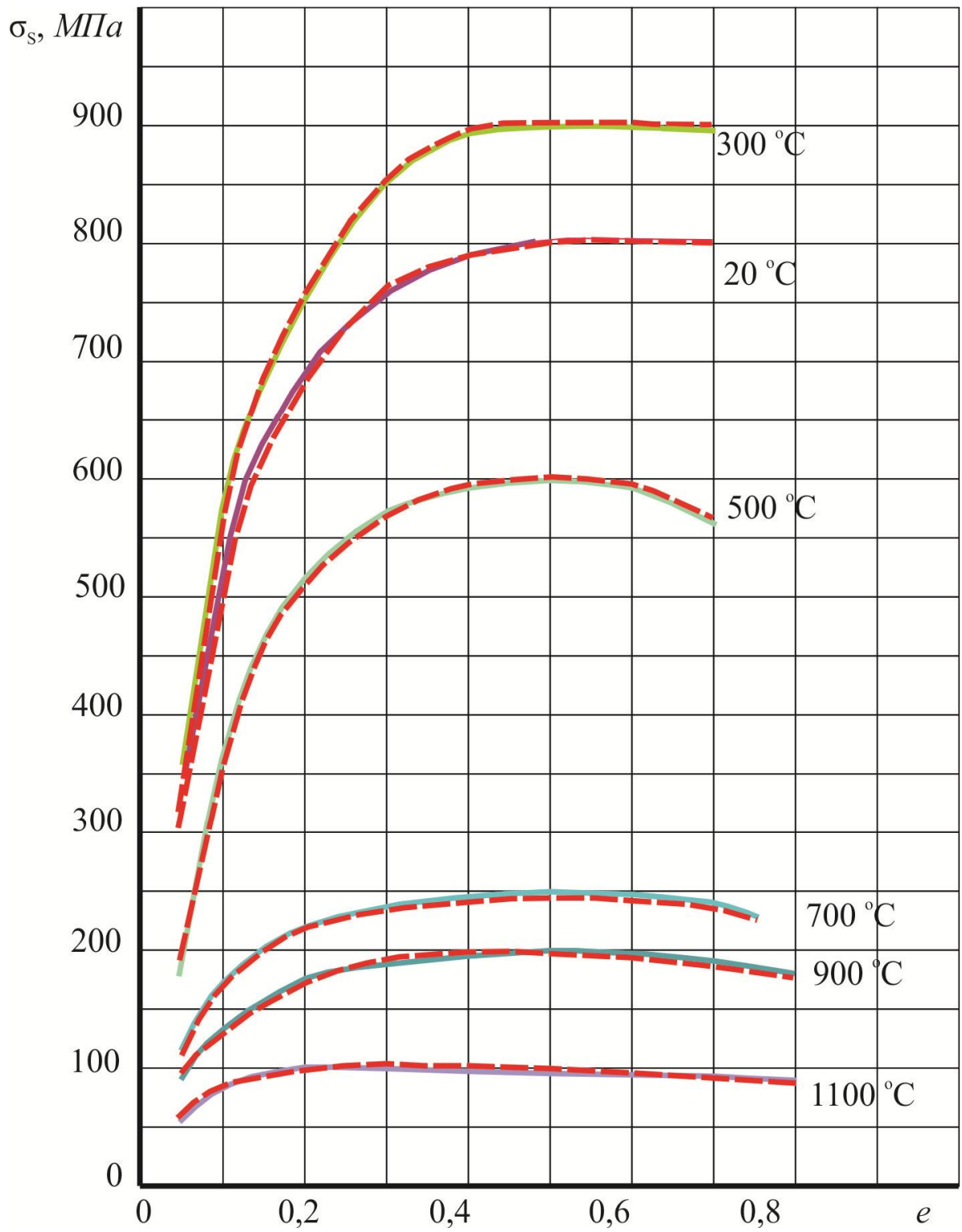

Рис.16. Кривые упрочнения стали 10 , полученные при осадке образцов круглого (сплошные линии) и квадратного (пунктирные линии) поперечного сечения при температурах $20-1100^{\circ} \mathrm{C}$ 
Результаты свидетельствуют о правомерности использования для осадки на пластометре образцов квадратного сечения вместо традиционных цилиндрических. При эффективной смазке, исключающей бочкообразование на боковой поверхности образцов, результаты определения сопротивления деформации практически совпадают с данными, полученными при осадке цилиндрических образцов.

\section{6. Заключение}

Модернизация кулачкового пластометра ЦКП «Пластометрия» ИМАШ УрО РАН, создание на его основе автоматизированного пластометрического комплекса с заменой релейной на современную тиристорную систему управления электроприводом и установкой цифровой системы сбора и обработки данных эксперимента с использованием ПЭВМ обеспечило повышение достоверности результатов определения сопротивления деформации сталей и сплавов.

Совершенствование известной методики осадки сплошных цилиндрических образцов позволило получить данные по сопротивлению деформации металлических материалов различного химического состава и структурного состояния в широком диапазоне изменения степеней, скоростей и температур деформации.

Разработка новой методики испытаний на осадку составных образцов обеспечивает возможность на пластометрическом комплексе определять сопротивление деформации листовых материалов, а использование образцов квадратного (прямоугольного) поперечного сечения упрощает подготовку к испытаниям, поскольку исключаются работы по изготовлению цилиндрических образцов. В данной работе на большом экспериментальном материале доказана правомерность применения новых методик.

Результаты работы позволили существенно расширить экспериментальную базу данных по сопротивлению деформации сталей и сплавов, необходимую для оптимизации и совершенствования технологии их обработки давлением.

\section{Благодарность}

Работа выполнена при частичной поддержке проекта ОФИ № 13-1-17-ЯЦ УрО РАН.

\section{Литература}

1. Горелик С. С., Добаткин С. В., Капуткина Л. М. Рекристаллизация металлов и сплавов. -3-е изд. - М. : МИСИС, 2005. - 432 с.

2. Полухин П. И., Гун Г. Я., Галкин А. М. Сопротивление пластической деформации металлов и сплавов. Справочник. - 2-е изд. перераб. и доп. - М. : Металлургия, 1983. - 352 с.

3. Computational modeling of the forward and reverse problems in instrumented sharp indentation / M. Dao, N. Chollacoop, K. J. Van Vliet, T. A. Venkatesh, S. Suresh // Acta materialia. 2001. - Vol. 49. - P. 3899-3918.

4. Determination of plastic properties of metals by instrumented indentation using different sharp indenters / J. L. Bucaille, S. Stauss, E. Felder, J. Michler // Acta materialia. - 2003. - Vol. 51. - P. 1663-1678.

5. Коновалов Д. А., Смирнов С. В., Вичужанин Д. И. Определение сопротивления деформации по результатам вдавливания конических инденторов // Известия вузов. Черная металлургия. - 2007. - № 3. - С. 69-70.

6. Smirnov S. V., Smirnova E. O. A technique for determining coefficients of the "stressstrain" diagram by nanoscratch test results // Journal of Materials Research. - 2014. - Vol. 29, № 16, P. 1730-1736. 
7. Методика исследований сопротивления деформации на пластометрическом комплексе / А. И. Потапов, В. П. Мазунин, Д. А. Двойников, Е. А. Коковихин // Заводская лаборатория. Диагностика материалов. - 2010. - Т. 76, № 9. - С. 59-63.

8. Хоникомб Р. Пластическая деформация металлов. - М. : Мир, 1972. - 406 с.

9. Мазунин В. П., Двойников Д. А. Повышение быстродействия при управлении регулируемыми электроприводами механизмов с упругими звеньями // Электротехника. - 2012. - № 10. - C. 36-42.

10. Зюзев А. М., Двойников Д. А. Реализация структуры быстродействующих электромеханических систем с помощью микроконтроллера тиристорного преобразователя постоянного тока Simoreg 6RA70 Siemens // Электротехнические системы и комплексы. - 2014. - № 4 (25). - C. 17-20.

11. Унксов Е. П. Инженерные методы расчета усилий при обработке металлов давлением. - М. : Машгиз, 1955. - 280 с.

12. Мигачев Б. А. Сопротивление деформации в механике обработки давлением. - Екатеринбург : УрО РАН, 1997. - 176 с.

13. Коновалов А. В., Смирнов А. С. Идентификация модели сопротивления деформации по результатам испытаний на сжатие образцов // Заводская лаборатория. Диагностика материалов. - 2010. - Т. 76, № 1. - С. 53-56.

14. Коновалов А. В., Смирнов А. С. Вязкопластическая модель сопротивления деформации стали 08X18Н10Т при температуре горячей деформации // Металлы. - 2008. - № 2. - С. 55-59.

15. Соколов Л. Д. К вопросу о деформационном старении // Физика металлов и металловедение. - 1962. - Т. 14, № 6. - С. 904-909.

16. Кроха В. А. Упрочнение металлов при холодной пластической деформации. Справочник. - М. : Машиностроение, 1980. - 157 с.

17. Теория ковки и штамповки: Учебное пособие для студентов машиностроительных и металлургических специальностей вузов. - 2-е изд.перераб. и доп. / Е. П. Унксов, У. Джонсон, В. Л. Колмогоров и др. - М. : Машиностроение, 1992. - 720 с.

18. Столяров В. В. Механические испытания на растяжение наноструктурных материалов // Заводская лаборатория. Диагностика материалов. - 2008. - Т. 74, № 1. - С. 54-57.

19. Определение сопротивления деформации листовых материалов / А. И. Потапов, С. В. Гладковский, Е. А. Коковихин, В. П. Мазунин // Заводская лаборатория. Диагностика материалов. - 2011. - Т. 76, № 6. - С. 52-56.

20. Логинов Ю. Н., Потапов А. И., Шалаев Н. А. Влияние температуры и скорости деформации на упрочнение титановой губки // Титан. - 2012. - № 3 (37). - С. 36-42. 